\title{
Selective Removal of Zinc from BOF Sludge by Leaching with Mixtures of Ammonia and Ammonium Carbonate
}

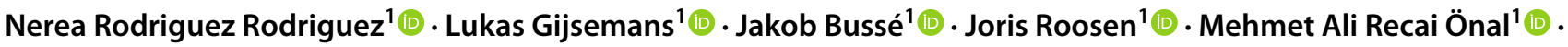

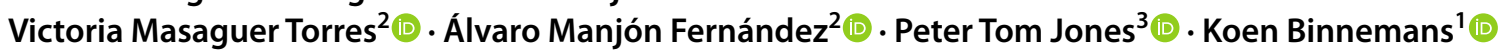

Received: 18 July 2020 / Accepted: 13 October 2020 / Published online: 9 November 2020

(C) The Author(s) 2020

\begin{abstract}
The zinc content of basic oxygen furnace (BOF) sludges is too high for direct recycling into the blast furnace via the sinter plant, as excessive zinc concentrations are detrimental for the refractory lining of the blast furnace. However, by partial and selective removal of zinc from the BOF sludge, the residual sludge can be used as a secondary iron resource in the blast furnace. In this paper, BOF sludge was leached with aqueous ammonia, aqueous solutions of ammonium salts (chloride, carbonate, and sulfate), and aqueous mixtures of ammonia and ammonium salt. The mixtures of ammonia and ammonium salt could leach more zinc with respect to either the aqueous ammonia or the aqueous ammonium salt solution. The ammonia-ammonium carbonate (AAC) mixture was selected as the most suitable lixiviant due to the high zinc leaching efficiency in combination with a high selectivity towards iron; furthermore, this combination does not introduce unwanted chloride or sulfate impurities in the residue. The leaching process was optimized in terms of the liquid-to-solid ratio, total ammonia concentration, ammonium:ammonia molar ratio, temperature, and leaching time. The co-dissolved iron was precipitated as a hydroxide after oxidation of ferrous to ferric ions by an air stream, without co-precipitation of zinc, while the dissolved zinc could be easily recovered as zinc sulfide by precipitation with ammonium sulfide. The (almost) closed-loop process was successfully up-scaled from $10 \mathrm{~mL}$ to $1 \mathrm{~L}$ scale.
\end{abstract}

\section{Graphical Abstract}

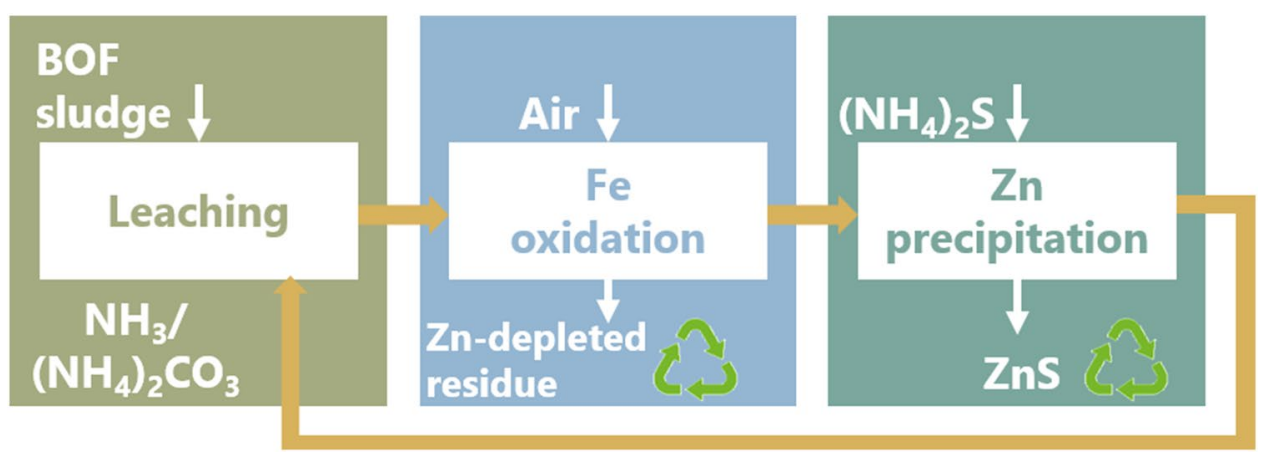

Keywords Ammoniacal leaching Ammonium salt leaching $\cdot$ Basic oxygen furnace sludge $\cdot$ Selective removal of zinc . Zinc recovery

The contributing editor for this article was Yongxiang Yang.

Electronic supplementary material The online version of this article (https://doi.org/10.1007/s40831-020-00305-3) contains supplementary material, which is available to authorized users.

Extended author information available on the last page of the article

\section{Introduction}

The average generation of basic oxygen furnace (BOF) dusts and sludges is approximately $22 \mathrm{~kg} /$ tonne of crude steel, with a minimum of $10 \mathrm{~kg} / \mathrm{tonne}$ of crude steel and a 
maximum of $40 \mathrm{~kg} /$ tonne of crude steel [1]. Due to improvements in the gas cleaning systems, more material is being collected rather than exiting into the atmosphere via exhaust stacks. This leads to slightly increasing production rates of BOF dusts and sludges over the years. Furthermore, generation of BOF dusts and sludges is expanding due to changes in process conditions, i.e., blowing rates, slag practices, bath additions, bath agitations.

BOF sludge predominantly consists of iron particles ejected from the BOF, which then partially oxidize within the gas cleaning system [1]. A study of the distribution of zinc in BOF off-gases of two ArcelorMittal steelmaking plants showed that the dust collected close to the BOF vessels contains much less zinc than the dust collected downstream in the off-gas cleaning system. The primary dust contains such a low zinc content, but rich in iron, that it has a good quality compared to virgin iron ores. Hence, it can be used as a secondary iron resource [2]. The average composition of the BOF sludge is about $60-75 \%$ iron, $0.3-1.6 \%$ of zinc, $1-2 \%$ carbon, and $1 \%$ lead [1]. A mineralogical study of BOF sludge from ArcelorMittal Monlevade (Brazil) showed that the following mineralogical phases were present both in the coarse and the fine fraction: wüstite $(\mathrm{FeO})$, magnetite $\left(\mathrm{Fe}_{3} \mathrm{O}_{4}\right)$, metallic iron $(\alpha-\mathrm{Fe})$, lepidocrocite $(\gamma-\mathrm{FeOOH})$, calcite $\left(\mathrm{CaCO}_{3}\right)$, and portlandite $\left(\mathrm{Ca}(\mathrm{OH})_{2}\right)$ [3]. Zincite $(\mathrm{ZnO})$ could not be identified, and the identification of franklinite $\left(\mathrm{ZnFe}_{2} \mathrm{O}_{4}\right)$ was not possible due to overlap with the peaks of magnetite in the X-ray diffractogram. Zinc speciation of $\mathrm{BOF}$ residue was found to be $43 \% \mathrm{ZnFe}_{2} \mathrm{O}_{4}$, $23 \% \mathrm{ZnCO}_{3}$, and $16 \% \mathrm{ZnO}$ [4]. The occurrence of $\mathrm{ZnCO}_{3}$ was attributed to the presence of limestone in the process. The zinc distribution and zinc speciation in a zinc-rich (3.4\% $\mathrm{ZnO}$ ) BOF sludge by micro-XRD and micro-XANES highlighted that the main zinc phases were franklinite $\left(\mathrm{ZnFe}_{2} \mathrm{O}_{4}\right)$ and smithsonite $\left(\mathrm{ZnCO}_{3}\right)[5,6]$. The composition and phase distribution of BOF sludges are showing a large variability, depending on the production plant and specific campaigns.

Due to the high iron and metallic iron content of BOF dusts and sludges, their recycling and recovery is of utmost importance. However, the high concentration of zinc and lead in these residues inhibits the internal recycling via the sinter plant/blast furnace (BF) route. When the zinc content is too high for recycling via the sinter plant/BF route, some steel plants blend materials and produce briquettes/ pellets, which are then charged back into the BOF vessels [1]. Another part of high-zinc BOF dust and sludge is temporarily stockpiled, and a significant part is recovered via the cement industry. There is a decreasing trend in landfilling of these materials, due to increasingly stringent environmental legislation and an increasing focus on waste minimization. The high moisture content of BOF sludge is a major obstacle in its recycling [7].

Different leaching technologies have been reported for the recovery of zinc from BOF sludge. These routes comprise leaching with mineral acids [8-12], leaching with organic acids [13, 14], alkali leaching [3, 15], and ammoniacal leaching [16-18]. The pros and cons of these routes are discussed below, while Table 1 briefly summarizes the main conclusions and challenges.

Although sulfuric acid can leach high amounts of zinc, the high iron co-dissolution represents a main disadvantage. A process for removing zinc from BOF sludge by leaching with spent pickling liquor $(\mathrm{HCl})$ was reported, where iron co-dissolution can be reduced by keeping the $\mathrm{pH}$ at 4-5 [12]. Organic acids have also been investigated for the recovery of zinc from BOF sludge $[13,14]$. The use of organic acids is justified because they are biodegradable and environmentally benign, which implies that the generation of harmful secondary wastes can be avoided. Furthermore, leaching with organic acids is, in general, more selective than leaching with inorganic acids. The reported leaching tests aimed to maximize zinc recovery while minimizing iron co-dissolution. Butyric acid was found to be the most efficient lixiviant, with $49.7 \% \mathrm{Zn}$ removal and $2.5 \%$ Fe leached. None of the organic acids could dissolve franklinite, which is a key phase in the BOF sludges.

Concurrently, alkaline leaching of BOF sludge with $5 \mathrm{M} \mathrm{NaOH}$ solution was found to be very selective for the removal of zinc over iron [3]. However, also in this case, the refractory franklinite phase was not dissolved. The zinc
Table 1 Summarized analysis of the technologies for the recovery of zinc from $\mathrm{BOF}$ sludge

\begin{tabular}{ll}
\hline Mineral acid leaching & $\begin{array}{l}\text { High zinc leaching efficiency but low selectivity of zinc over iron } \\
\text { Franklinite can be dissolved }\end{array}$ \\
Organic acid leaching & $\begin{array}{l}\text { Lower zinc leaching efficiency and higher selectivity compared to } \\
\text { mineral acids } \\
\text { More environmentally friendly than mineral acids }\end{array}$ \\
& Franklinite cannot be dissolved \\
Very selective removal of zinc over iron \\
Alkali leaching & Figh reagent consumption \\
& Franklinite cannot be dissolved without thermal pretreatment \\
Ammoniacal leaching & Lery selective removal of zinc over iron \\
& Franklinite cannot be dissolved without thermal pretreatment
\end{tabular}


recovery was only between 40 and 60\%. However, franklinite could be decomposed by thermal treatment with $\mathrm{NaOH}$ $\left(T=450{ }^{\circ} \mathrm{C}, t=1-5 \mathrm{~h}, \mathrm{NaOH} / \mathrm{sludge}\right.$ ratio $\left.=0.75\right)$, and subsequently leached with $5 \mathrm{M} \mathrm{NaOH}$ resulting in $94 \%$ of zinc removal. However, the main disadvantage of the latter method is the large reagent consumption, which is detrimental for the cost-effectiveness of this treatment.

Although ammoniacal leaching has been widely explored for the valorization of by-products from the steelmaking industry $[17,19-26]$, it has barely been applied to BOF sludges. Only one study investigated the use of aqueous ammonia or aqueous solutions of ammonium salts for leaching of BOF sludge [18]. A recent patent describes the ammoniacal leaching of zinc from BF and BOF sludges, but a roasting pretreatment step was required to get high zinc dissolution [27]. In the present study, the leaching of BOF sludge using aqueous ammonia, an aqueous solution of ammonium salt, and also an aqueous mixture of ammonia and ammonium salt was investigated, in view of finding a cost-effective BOF sludge treatment methodology. The ammonia-ammonium carbonate (AAC) mixture was found to be the most suitable combination. The precipitation of the co-dissolved iron, and the recovery of the dissolved zinc from the pregnant leach solution was also studied. The present work proposes a closed-loop process for the recovery of zinc from BOF sludge using AAC leaching.

\section{Experimental}

\section{Chemicals}

Hydrochloric acid, $\mathrm{HCl},(>37 \%)$, ammonium sulfate, $\left(\mathrm{NH}_{4}\right)_{2} \mathrm{SO}_{4},(>99.5 \%)$, and ammonia, $\mathrm{NH}_{3},(25 \%)$ were purchased from VWR (Fontenay-sous-Bois, France). Nitric acid, $\mathrm{HNO}_{3},(>65 \%)$ and ammonium chloride, $\mathrm{NH}_{4} \mathrm{Cl}$, (>99.8\%) were obtained from Chem-Lab NV (Zedelgem, Belgium). Ammonium carbonate, $\left(\mathrm{NH}_{4}\right)_{2} \mathrm{CO}_{3},(99.5 \%)$ and ammonium sulfide solution, $\left(\mathrm{NH}_{4}\right)_{2} \mathrm{~S}, 20 \mathrm{wt} \%$ in water, were purchased from Sigma-Aldrich (Overijse, Belgium). Standard solutions of gallium and gadolinium $(1000 \mu \mathrm{g} \mathrm{mL}$ in 2-5 vol\% $\mathrm{HNO}_{3}$ ) were obtained from Merck (Overijse, Belgium). A silicon solution in isopropanol was purchased from SERVA Electrophoresis GmbH (Heidelberg, Germany). Water was always of ultrapure quality, deionized to a resistivity of $18.2 \mathrm{M} \Omega \mathrm{cm}$ with a Millipore ultrapure water system. All chemicals were used as received without any further purification. The BOF sludges were kindly provided by the ArcelorMittal steel plant in Bremen (Germany).

\section{Instrumentation}

The material was ground and sieved using a mortar grinder (Fritsch, Pulverisette 2) and a vibratory sieve shaker (Fritsch, Analysette 3). The metal content of the different samples was measured using a benchtop Total Reflection X-ray Fluorescence (TXRF) spectrometer (Bruker, S2 Picofox). X-ray powder diffraction (XRD) was used for the phase identification of the crystalline fraction (Bruker D2 Phaser). Experimental parameters for XRD analysis were $2 \theta=20^{\circ}-90^{\circ}$, radiation $=\mathrm{CuK}_{\alpha}$, acceleration voltage $=40 \mathrm{kV}$, acceleration current $=40 \mathrm{~mA}$, a step size of $0.020^{\circ}$, and a counting time of $1 \mathrm{~s}$ per step, spin mode. The X'Pert HighScore software was used to analyze the collected data by comparison with the ICDD (International Centre for Diffraction Data). Electron probe microanalysis (EPMA) was performed on a JEOL JXA-8530FTMS-300 apparatus, operated at an acceleration voltage of $15 \mathrm{kV}$ and an electrical current of $5 \times 10^{-8}$ A was used to characterize the BOF sludge. Thermoshakers from ThermoFisher Scientific were used to mix the vials of the leaching experiments. A Heraeus D-6450 oven was employed to dry the solid samples. For the large-scale experiments, a $1 \mathrm{~L}$ glass reactor (HiTec Zang, Herzogenrath, Germany) was used.

\section{Procedure}

The received samples were dried in a ventilated oven at $80{ }^{\circ} \mathrm{C}$ for $48 \mathrm{~h}$, milled and sieved ( $250 \mu \mathrm{m}$ pore size mesh). The composition of the BOF sludge was determined by total digestion of the solid sample, followed by TXRF analysis. For the digestion, $5 \mathrm{~mL}$ of aqua regia was added to a glass vial containing $50 \mathrm{mg}$ of dried, milled, and sieved sludge. After $10 \mathrm{~min}$, the lid was placed on the vial but it was not tightly closed to avoid pressure build-up due to the production of fumes. The mixture was left to react for $24 \mathrm{~h}$. Afterwards, the metal content of the digested samples was measured via TXRF. Throughout the entire work, the sample preparation for the TXRF measurements was as follows: the sample was diluted in a nitric acid solution (2 vol\%) and internal standards (ISs) were added (gadolinium and gallium). The dilution factor was chosen so that the final concentration was lower than $100 \mathrm{mg} \mathrm{L}^{-1}$. Silicone solution SERVA $(30 \mu \mathrm{L})$ was added on the carrier surface and dried for $5 \mathrm{~min}$ at $60^{\circ} \mathrm{C}$ in a hot air oven. A small droplet $(5 \mu \mathrm{L})$ of the diluted sample was added onto the hydrophobized carrier. Then, the carrier was dried in a hot air oven for $30 \mathrm{~min}$ at $60{ }^{\circ} \mathrm{C}$. More experimental details about the TXRF analysis procedure can be found in the literature [28]. 
For the leaching experiments, $1 \mathrm{~g}$ of sample was added to a glass vial, the lixiviant was added, and the vial was closed and mixed using the Thermo shakers. After leaching, the pregnant leach solution and the residue were separated by syringe filtration (PET, $0.45 \mu \mathrm{m}$ ). Immediately after the filtration, the required amount of sample for the TXRF analysis was pipetted and placed in a vial containing the required amount of $\mathrm{HNO}_{3}(2 \mathrm{vol} \%)$ for the dilution. In the case of multiple contact leaching experiments, the separation of the PLS was performed by vacuum filtration. The solid residue was dried in the oven for characterization before the next leaching experiment, and the composition of the PLS was analyzed. All the experiments were done in triplicate, and each sample within the triplicate was measured once. The standard deviations were calculated based on the measured values of this triplicate.

The precipitation of iron from the filtered PLS via both spontaneous oxidation of ferrous to ferric ions and forced oxidation by an air stream was investigated. For the spontaneous oxidation experiments, the filtered PLS was left in an open vial, while for the forced oxidation, air was bubbled through the samples. At the specified time intervals, a small aliquot of the sample was taken and analyzed via TXRF.

For the zinc recovery experiments, the required amount of ammonium sulfide was added to the filtered iron-free PLS and stirred at room temperature. Then the mixture was centrifuged and filtered. The zinc content of the remaining liquid was analyzed via TXRF. The precipitate was washed with MilliQ water and dried at $60{ }^{\circ} \mathrm{C}$ to determine its dry mass. The precipitate was digested in hydrochloric acid, while the metal content was measured by TXRF.

\section{Results and Discussion}

\section{Characterization of BOF Sludge}

The BOF sludges used in this work were collected before the filter press. The materials were dried, ground, and sieved, and only the fraction smaller than $250 \mu \mathrm{m}$ was used (Fig. $\mathrm{S} 1)$. The chemical composition was determined via digestion in aqua regia, followed by TXRF analysis. Two samples of BOF sludge were used in this work, namely BOF1 and BOF2. Both materials were from the same steel plant, but collected at different times. The composition of BOF1 was $55.37 \pm 1.85 \mathrm{wt} \%$ iron and $6.73 \pm 0.10 \mathrm{wt} \%$ zinc and that of BOF2 was $52.38 \pm 1.76 \mathrm{wt} \%$ iron and $6.04 \pm 0.20 \mathrm{wt} \%$ zinc. The mineralogical analysis of the powdered sample showed that the main phases present in the sludge were carbon $(\mathrm{C})$, free iron $(\mathrm{Fe})$, wüstite $(\mathrm{FeO})$, and calcite $\left(\mathrm{CaCO}_{3}\right)$, along with magnetite $\left(\mathrm{Fe}_{3} \mathrm{O}_{4}\right)$ and/or franklinite $\left(\mathrm{ZnFe}_{2} \mathrm{O}_{4}\right)$, and zincite $(\mathrm{ZnO})$, (Fig. 1). This is in agreement with what has been previously reported in the literature [3-6]. The

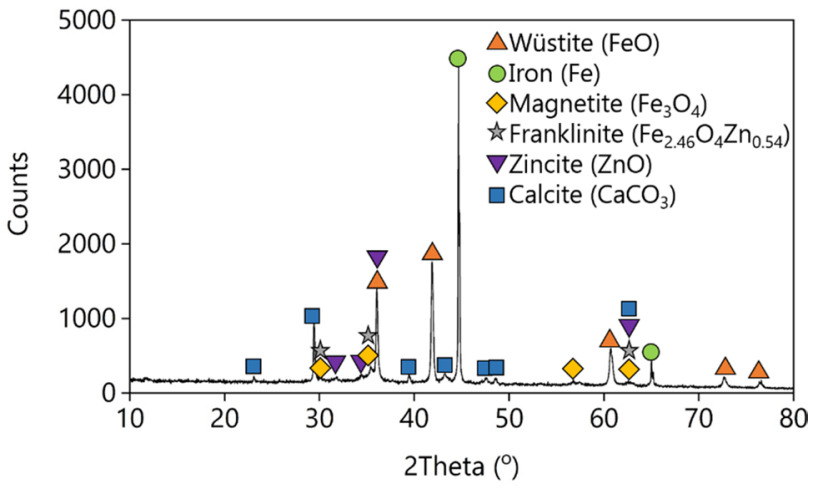

Fig. 1 XRD pattern of BOF1 sludge

differentiation between magnetite and franklinite phases via XRD analysis is difficult due to the overlapping of their low-intensity characteristic diffraction peaks throughout the pattern, and because franklinite and magnetite are end members of solid solution series. Hence, the sample was also analyzed for elemental mapping of zinc, iron, and oxygen with EPMA-WDS. Backscattered electron (BSE) images of the powder along with respective elemental mappings are provided in Fig. 2 and in the supporting information (SI) (Figs. S2, S3, S4, and S5). The regions dominated by varying shades of turquoise and green are rich in iron indicating metallic iron or its oxide(s) (i.e., magnetite and wüstite). Zinc-rich regions are represented by red and pink indicating zinc oxide or zinc present in a solid solution between wüstite and zincite, $(\mathrm{Fe}, \mathrm{Zn}) \mathrm{O}$. Free zinc cannot be present under $\mathrm{BOF}$ conditions. Blue regions represent oxides of metals in the sample other than zinc and iron. Finally, gray and yellow regions show the regions where zinc and iron are concentrated, indicating franklinite sites. Based on this analysis, it can be concluded that zinc is mainly distributed between its simple oxide and the hard-to-dissolve, refractory magnetite-franklinite solid solution phase.

\section{Selection of Lixiviant}

In the BOF sludge, both the zinc and (most of) the iron are present in the divalent state, as wüstite, zincite or a solid solution between wüstite and zincite. The ammoniacal leaching of zinc is thermodynamically feasible because of the favorable stability of the tetrammine zinc(II) complex $\left[\mathrm{Zn}\left(\mathrm{NH}_{3}\right)_{4}\right]^{2+}$, as demonstrated by the predominance diagrams, and the high value of the stability constant [29]. The solubility of $\mathrm{Fe}(\mathrm{II})$ in aqueous ammonia is very low, although the hexaammine iron(II) complex $\left[\mathrm{Fe}\left(\mathrm{NH}_{3}\right)_{6}\right]^{2+}$ can be formed under certain conditions [30]. When the ferrous ion $\mathrm{Fe}(\mathrm{II})$ in solution is oxidized to the ferric ion $\mathrm{Fe}(\mathrm{III})$, it precipitates as $\mathrm{Fe}(\mathrm{OH})_{3}$ because the hexaammine iron(III) $\left[\mathrm{Fe}\left(\mathrm{NH}_{3}\right)_{6}\right]^{3+}$ is not stable. 

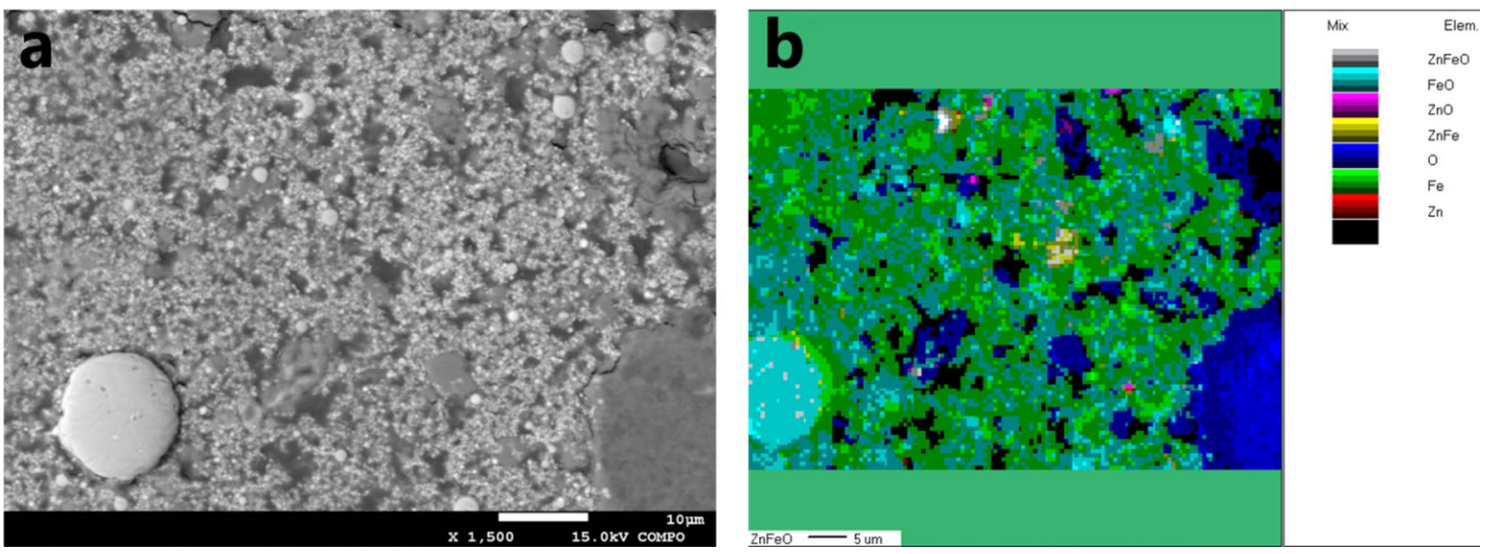

Fig. 2 EPMA measurements on BOF sample: a backscattered electron (BSE) image and b superimposed elemental maps of Zn, O, and Fe (scale in color intensity) (Color figure online)

When BOF1 sludge was leached with aqueous ammonia $\left(\left[\mathrm{NH}_{3}\right]=13.6 \mathrm{M}, T=60^{\circ} \mathrm{C} ; t=3 \mathrm{~h}\right.$; liquid-to-solid ratio, $L / S=3 \mathrm{~mL} / \mathrm{g}$ ), only a small fraction of the zinc was dissolved $(10.3 \%)$ with minor co-dissolution of iron $(<0.1 \%)$. The obtained solubility of zinc is much lower than what would be expected based on the stability of the $\left[\mathrm{Zn}\left(\mathrm{NH}_{3}\right)_{4}\right]^{2+}$ complex. Unexpectedly low or negligible $\mathrm{ZnO}$ solubility has been previously reported in aqueous ammonia and $\mathrm{NaOH}$ solutions $[3,18,19]$. A possible reason for this behavior could be the high $\mathrm{pH}$, at which the zinc complexes are not favorable, or that zinc could precipitate as $\mathrm{Zn}(\mathrm{OH})_{2}$ [29]. A similar behavior has been reported for the ammoniacal leaching of chrysocolla, and it was suggested that free ammonia is not the active species in the ammoniacal leaching of copper (which is also based on the formation of tetraammine complexes), but rather the ammonium ion [31]. However, a more plausible reason for the limited leaching of zinc in ammonia solution is the fact that a counter anion is required for the charge balance with the $\left[\mathrm{Zn}\left(\mathrm{NH}_{3}\right)_{4}\right]^{2+}$ complex and that the only anion present in ammonia solution is the hydroxide ion, which forms a poorly soluble complex with $\left[\mathrm{Zn}\left(\mathrm{NH}_{3}\right)_{4}\right]^{2+}$.

The use of aqueous solutions of ammonium salts or aqueous mixtures of ammonia-ammonium salts increases the zinc leaching efficiency, due to the presence of anions stabilizing the $\left[\mathrm{Zn}\left(\mathrm{NH}_{3}\right)_{4}\right]^{2+}$ complex (apart from $\mathrm{OH}^{-}$), as well as the lower $\mathrm{pH}$ associated to the presence of ammonium salts. BOF1 was leached with aqueous solutions of $\mathrm{NH}_{4} \mathrm{Cl},\left(\mathrm{NH}_{4}\right)_{2} \mathrm{CO}_{3},\left(\mathrm{NH}_{4}\right)_{2} \mathrm{SO}_{4}$, and $\left\{\mathrm{NH}_{4} \mathrm{Cl}+\mathrm{NH}_{3}\right\}$, $\left\{\left(\mathrm{NH}_{4}\right)_{2} \mathrm{CO}_{3}+\mathrm{NH}_{3}\right\}$, and $\left\{\left(\mathrm{NH}_{4}\right)_{2} \mathrm{SO}_{4}+\mathrm{NH}_{3}\right\}$ mixtures. For comparison purposes, the total \{ammonium + ammonia\} concentration $\left(\left[\mathrm{NH}_{4}{ }^{+}+\mathrm{NH}_{3}\right]\right)$ was kept constant at $3 \mathrm{M}$, and for the mixtures the ammonium:ammonia molar ratio, $\left(\mathrm{NH}_{4}^{+}: \mathrm{NH}_{3}\right)$, was kept at 1:1. The obtained results are present in Fig. 3.

Figure 3a shows that higher leaching efficiencies of zinc can be obtained with aqueous solutions of ammonium salts instead of aqueous ammonia. The leaching efficiency of zinc increased in the order $\left(\mathrm{NH}_{4}\right)_{2} \mathrm{CO}_{3}<\left(\mathrm{NH}_{4}\right)_{2} \mathrm{SO}_{4}<\mathrm{NH}_{4} \mathrm{Cl}$. The higher zinc leaching efficiency with $\mathrm{NH}_{4} \mathrm{Cl}$ compared to $\left(\mathrm{NH}_{4}\right)_{2} \mathrm{CO}_{3}$ has been previously reported for BOF sludges [18]. Thermodynamic studies showed that the tetraammine zinc(II) complex is more stable than any of the chloro complexes, and that the role of the chloride ion is to stabilize the complex $[29,32]$. The same has been reported for the carbonate system [17]. Therefore, the differences in the zinc solubility are attributed to the capacity of the anion salt to stabilize the tetraammine zinc(II) complex. An increase in the iron leaching efficiency was also noticed for the ammonia-ammonium salt system. It has previously been reported that the solubility of iron in the ferrous oxidation state can be surprisingly large in concentrated aqueous ammoniacal solutions containing an anion. In order to solubilize iron, ammonia needs to be added in excess with respect to the solute and a sufficient amount of conjugate ions need to be present to combine with a divalent cationic complex. These conditions are necessary to form the ammonia ligands. Otherwise, the ammonia is replaced by water and the iron becomes insoluble [30].

The addition of an excess of ammonia to the ammonium salt increased the leaching efficiency of zinc in all the cases, especially for $\left(\mathrm{NH}_{4}\right)_{2} \mathrm{CO}_{3}$. The zinc leaching efficiency of the ammonia-ammonium mixture increased in the order $\left(\mathrm{NH}_{4}\right)_{2} \mathrm{SO}_{4}<\left(\mathrm{NH}_{4}\right)_{2} \mathrm{CO}_{3}<\mathrm{NH}_{4} \mathrm{Cl}$. The excess of ammonia favors the zinc solubility due to the formation of soluble ammine complexes. The addition of $\mathrm{NH}_{3}$ reduced the leaching efficiency for iron (i.e., increased the selectivity) in the $\left(\mathrm{NH}_{4}\right)_{2} \mathrm{CO}_{3}$ and the $\left(\mathrm{NH}_{4}\right)_{2} \mathrm{SO}_{4}$ systems, but not in the $\mathrm{NH}_{4} \mathrm{Cl}$ system. The leaching efficiency for zinc is higher than that for iron in all the systems. However, the concentration of zinc in the PLS was not always higher due the large difference in concentration of the initial residue $(\mathrm{Fe}=55.0 \%$, $\mathrm{Zn}=6.7 \%$ ). Figure 3 shows the composition of fresh PLS, 
Fig. 3 a Effect of the type of ammonium salt or its mixture with ammonia solution on the leaching efficiency of BOF1. Leaching conditions: $T=60{ }^{\circ} \mathrm{C} ; t=24 \mathrm{~h} ; L / S=10 \mathrm{~mL} / \mathrm{g}$. Concentration of $\mathbf{b}$ iron and $\mathbf{c}$ zinc in the pregnant leach solution, fresh and after $24 \mathrm{~h}$. BOF1. Leaching conditions: $T=60^{\circ} \mathrm{C} ; t=24 \mathrm{~h} ; L / S=10 \mathrm{~mL} / \mathrm{g}$; BOF1

where the selectivity of the studied systems can be easily assessed. For the systems containing $\left(\mathrm{NH}_{4}\right)_{2} \mathrm{SO}_{4}$, the concentration of iron in the PLS was higher than that of zinc. Aqueous solutions of $\mathrm{NH}_{4} \mathrm{Cl}$ are selective for zinc, but the selectivity decreased upon addition of an excess of ammonia. The systems containing $\left(\mathrm{NH}_{4}\right)_{2} \mathrm{CO}_{3}$ are the most selective towards iron. Based on the zinc leaching efficiency, both the $\left\{\left(\mathrm{NH}_{4}\right)_{2} \mathrm{CO}_{3}+\mathrm{NH}_{3}\right\}$ and the $\left\{\mathrm{NH}_{4} \mathrm{Cl}+\mathrm{NH}_{3}\right\}$ mixtures are promising. However, the $\left\{\left(\mathrm{NH}_{4}\right)_{2} \mathrm{CO}_{3}+\mathrm{NH}_{3}\right\}$ system is preferred due to the larger selectivity towards iron and the absence of corrosive chloride ions. The presence of chloride ions in the solid leaching residue could damage the blast furnace.

The filtered PLS obtained from the leaching of BOF sludge with ammonium salts or ammonia-ammonium salts mixtures was not stable over time; a brown precipitate appeared after the filtration of PLS. This precipitation corresponds to the formation of $\mathrm{Fe}(\mathrm{OH})_{3}$ due to oxidation of the $\mathrm{Fe}(\mathrm{II})$ ion, dissolved as $\left[\mathrm{Fe}\left(\mathrm{NH}_{3}\right)_{4}\right]^{2+}$, to the $\mathrm{Fe}(\mathrm{III})$ ion by contact with air. The precipitation might have started during the leaching step, but it continues after the filtration until all the dissolved iron has been precipitated as $\mathrm{Fe}(\mathrm{OH})_{3}$. This behavior was not observed when leaching with aqueous ammonia due to the lower solubility of Fe(II) in the form of $\mathrm{Fe}(\mathrm{OH})_{2}$.

The filtered PLSs were kept in a closed vial for $24 \mathrm{~h}$ (Fig. S6), and the composition was measured and compared to the composition of the PLS immediately after filtration. Figure 3 shows that the concentration of zinc in the PLS remained constant over time, while the concentration of iron had largely decreased. This phenomenon can be exploited to increase the selectivity for zinc, as will be shown later in this study. However, unless otherwise stated, the leaching efficiencies and compositions of the PLS have been calculated from the composition of the fresh PLS.

\section{Optimization of the Leaching Process}

AAC leaching was optimized in terms of liquid-to-solid ratio (Fig. 4, Table S1), $\mathrm{NH}_{4}{ }^{+}: \mathrm{NH}_{3}$ molar ratio (Fig. 4, Table S2), and total $\left[\mathrm{NH}_{4}{ }^{+}+\mathrm{NH}_{3}\right]$ concentration (Fig. 4, Table S3). Due to the limited availability of BOF1, the optimization was performed using a different BOF sludge sample (BOF2). The compositions of both residues were similar (see characterization section) and the leaching behavior was found to be identical (Fig. S7). The leaching efficiency for both zinc and iron increased while enhancing the $L / S$ ratio (Fig. 4).
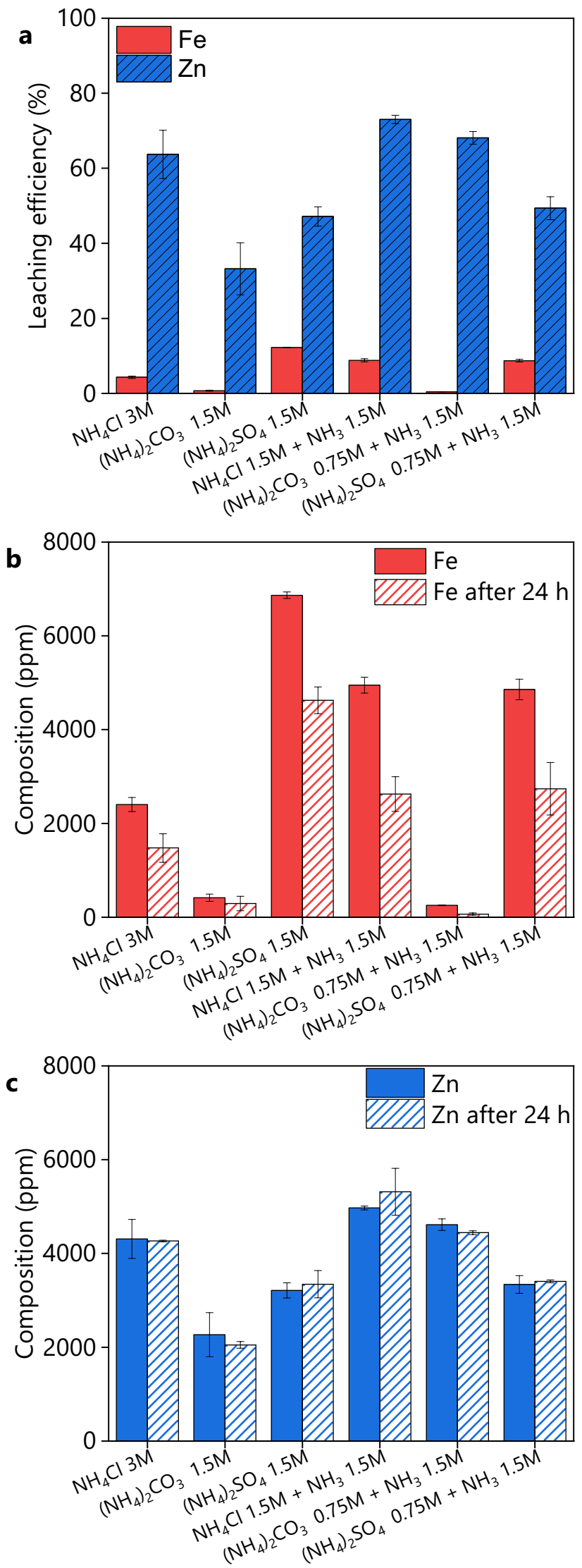
Fig. 4 a Effect of the $L / S$ on the leaching efficiency of the BOF sludge. The leaching conditions were $T=60{ }^{\circ} \mathrm{C} ; t=3 \mathrm{~h}$; $\left[\mathrm{NH}_{4}{ }^{+}+\mathrm{NH}_{3}\right]=3 \quad \mathrm{M} ; \quad \mathrm{NH}_{4}{ }^{+}: \mathrm{NH}_{3}=1: 1$. b Effect of the $\mathrm{NH}_{4}^{+}: \mathrm{NH}_{3}$ ratio on the leaching efficiency of the BOF2 sludge. The leaching conditions were $T=60{ }^{\circ} \mathrm{C} ; t=3 \mathrm{~h} ; L / S=10 \mathrm{~mL} / \mathrm{g}$; $\left[\mathrm{NH}_{4}{ }^{+}+\mathrm{NH}_{3}\right]=3 \mathrm{M}$. c Effect of the total ammonia concentration $\left[\mathrm{NH}_{4}{ }^{+}+\mathrm{NH}_{3}\right]$ on the leaching efficiency of the BOF2 sludge. The leaching conditions were $T=60{ }^{\circ} \mathrm{C} ; t=3 \mathrm{~h} ; L / S=10 \mathrm{~mL} / \mathrm{g}$; $\mathrm{NH}_{4}{ }^{+}: \mathrm{NH}_{3}=1: 2$

Table S1 shows that an increase in the $L / S$ ratio decreased the selectivity against iron. Since the primary objective of this work was to obtain a solid residue with low zinc content to be fed into the blast furnace, high leaching efficiencies are preferred.

AAC system could leach more zinc than either aqueous ammonia or an aqueous solution of ammonium carbonate separately (Fig. 3). The effect of the $\mathrm{NH}_{4}{ }^{+}: \mathrm{NH}_{3}$ molar ratio on the leaching efficiency of zinc was investigated (Fig. 4b, Table S2), and an optimum $\mathrm{NH}_{4}{ }^{+}: \mathrm{NH}_{3}$ molar ratio of $1: 1$ was identified when leaching with $\left[\mathrm{NH}_{4}^{+}+\mathrm{NH}_{3}\right]$ at $3 \mathrm{M}$. Further increase of ammonia or ammonium carbonate ratio decreased the zinc leaching efficiency. This is consistent with $\mathrm{CO}_{3}{ }^{2+}: \mathrm{NH}_{3}$ molar ratio of 1:4 required for the formation of the soluble $\left[\mathrm{Zn}\left(\mathrm{NH}_{3}\right)_{4}\right] \mathrm{CO}_{3}$ species. This ratio has been reported as optimal in other studies, but, in general, there is disagreement on which value is optimal [17]. In another paper, the effect of the $\mathrm{NH}_{4}{ }^{+}: \mathrm{NH}_{3}$ ratio was reported to be negligible [20]. The latter used high total ammonia concentrations. In additional experiments performed with our BOF material, we have confirmed that at higher total ammonia concentrations the effect of the $\mathrm{NH}_{4}^{+}: \mathrm{NH}_{3}$ ratio is negligible in the 2:1 to 1:2 region. Based on the literature data and our experimental results, it can be concluded that the optimal $\mathrm{NH}_{4}^{+}: \mathrm{NH}_{3}$ is highly dependent on the total amount of ammonia and the mean solid-to-liquid ratio.

Figure 4 shows that increasing the total ammonia concentration increased the leaching efficiency for both zinc and iron. In this work, a total ammonia concentration of $4 \mathrm{M}$ was selected as the optimal value because further increase in the concentration did not significantly enhance the leaching efficiency for zinc, but it increased the leaching efficiency for iron. At this concentration, the effect of the $\mathrm{NH}_{4}{ }^{+}: \mathrm{NH}_{3}$ ratio was negligible, and a ratio of 1:2 was selected for the further experiments.

The leaching time and temperature were simultaneously optimized for BOF2 (Fig. 5). Independently of the leaching temperature, the leaching efficiency of zinc increased with the leaching time until $\approx 24 \mathrm{~h}$ of leaching, after which the leaching of zinc decreased with time. This behavior has been previously reported in the literature; it was attributed to the precipitation of zinc as franklinite [18, 33]. Increasing the temperature enhanced the leaching efficiency for zinc. The
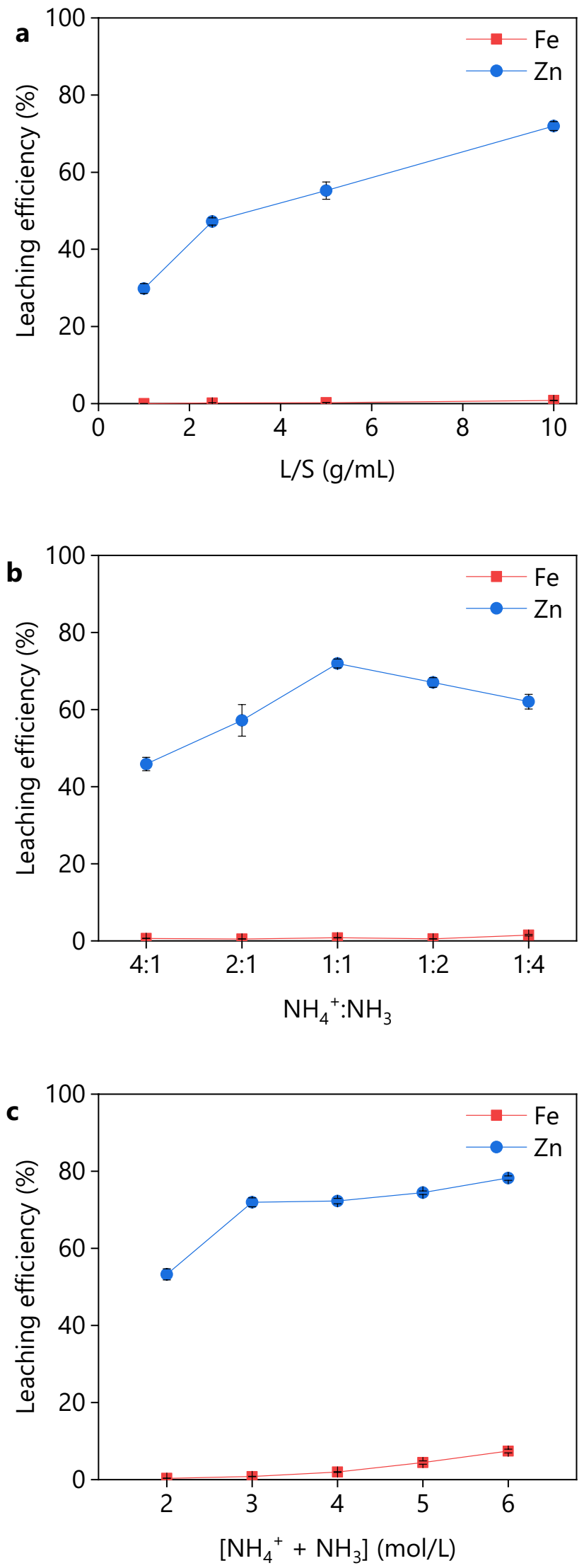

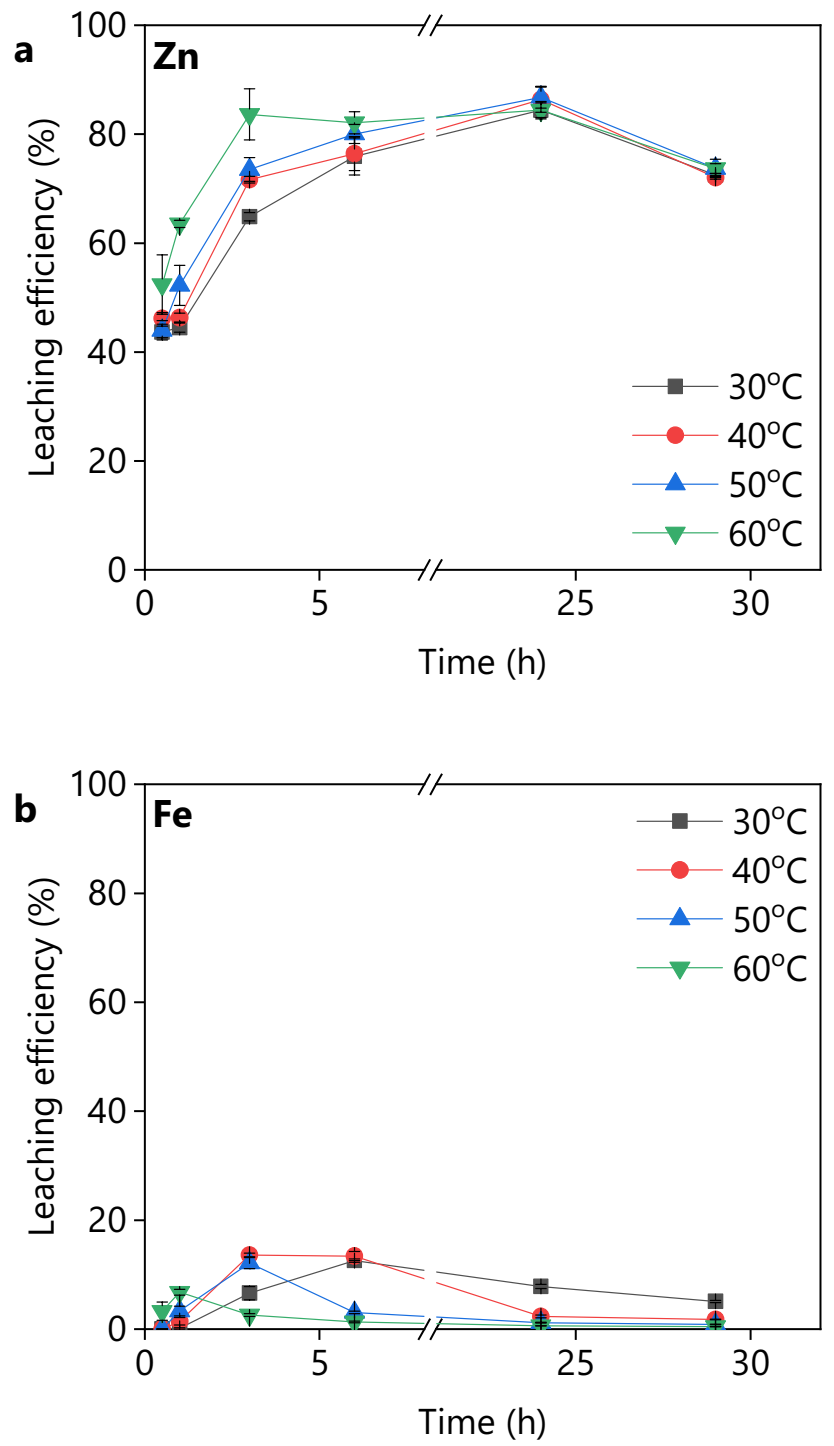

Fig. 5 Effect of the leaching time on the leaching efficiency of BOF sludge at different temperatures of: $\mathbf{a}$ zinc and $\mathbf{b}$ iron. The leaching conditions were $L / S=10 \quad(\mathrm{~mL} / \mathrm{g}) ; \quad \mathrm{NH}_{4}{ }^{+}: \mathrm{NH}_{3}=1: 2$; $\left[\mathrm{NH}_{4}^{+}+\mathrm{NH}_{3}\right]=4 \mathrm{M}$

leaching efficiency for iron initially increased with the leaching time, but after certain time, it decreased. The time at which the maximum iron leaching efficiency was obtained, depended on the leaching temperature. The higher the temperature, the faster the maximum was reached. This behavior is attributed to the precipitation of iron in the form of $\mathrm{Fe}(\mathrm{OH})_{3}$. Based on the obtained results, a leaching time of $6 \mathrm{~h}$ and a temperature of $60^{\circ} \mathrm{C}$ can be considered as optimal, but longer leaching times at lower temperatures can produce the same results.

In an effort to reduce the amount of lixiviant, the performance of a multiple contact leaching was studied. At each step, the solid was contacted with fresh lixiviant at $L / S=2.5$.

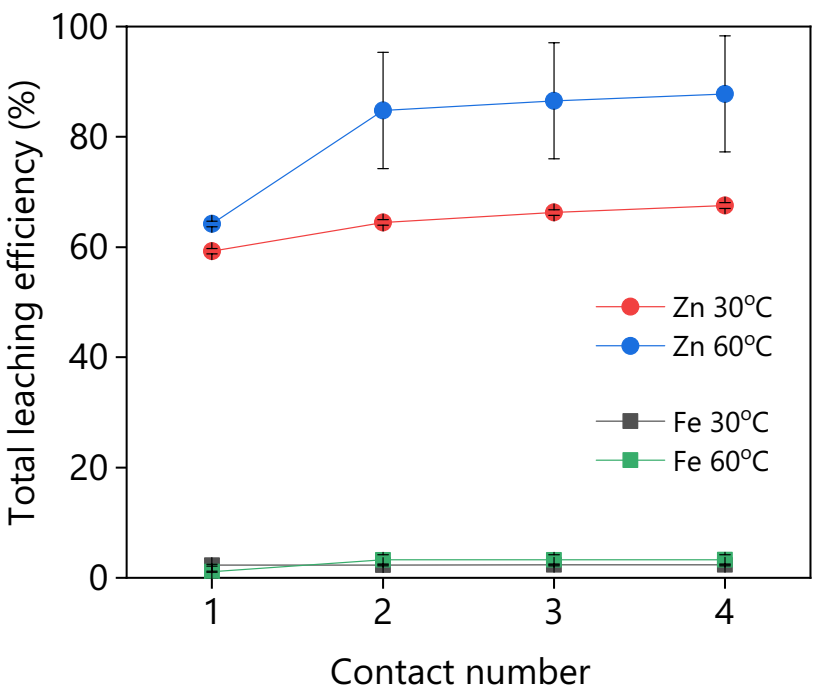

Fig. 6 Cumulative leaching efficiency after multiple contact leaching of BOF sludge with lixiviant. The leaching conditions were $t=3 \mathrm{~h}$; $L / S=2.5(\mathrm{~mL} / \mathrm{g})$ each step; $\mathrm{NH}_{4}{ }^{+}: \mathrm{NH}_{3}=1: 2 ;\left[\mathrm{NH}_{4}{ }^{+}+\mathrm{NH}_{3}\right]=4 \mathrm{M}$

Figure 6 shows that after two contacts, i.e., corresponding to a total $L / S$ of 5 , the leaching of zinc was negligible. The leaching efficiency for zinc at $30^{\circ} \mathrm{C}$ was about $60 \%$ already after just one contact, and it did not increase after multiple leaching steps. Therefore, the combination of low $L / S$ and low temperatures is not suitable for the leaching of zinc (Fig. 6). In the multiple contact leaching at $60^{\circ} \mathrm{C}$, the large error bars can be attributed to issues during the sample handling (i.e., the reason why the composition of the leaching residue after the second contact could not be measured, Table 2). Since this experiment was sequential, a significant cumulative measurement error occurred, but from the average values a trend can still be observed.

The composition of the solid residue after each contact is shown in Table 2. The results corroborate that the zinc concentration did not further decrease after the second leaching contact, while the iron concentration did. The zinc content of the leaching residue obtained after two leaching steps at

Table 2 Composition of dried BOF sludge residue after leaching steps

\begin{tabular}{llllll}
\hline $\begin{array}{l}\text { Contact } \\
\text { number }\end{array}$ & \multicolumn{2}{l}{$T=30^{\circ} \mathrm{C}$} & & $T=60{ }^{\circ} \mathrm{C}$ & \\
\cline { 2 - 3 } \cline { 5 - 6 } & $\mathrm{Fe}(\mathrm{wt} \%)$ & $\mathrm{Zn}(\mathrm{wt} \%)$ & $\mathrm{Fe}(\mathrm{wt} \%)$ & $\mathrm{Zn}(\mathrm{wt} \%)$ \\
\hline 0 & $55.7 \pm 1.8$ & $5.5 \pm 0.5$ & & $55.7 \pm 1.8$ & $5.5 \pm 0.5$ \\
1 & $50.7 \pm 1.2$ & $2.9 \pm 0.1$ & & $47.7 \pm 2.1$ & $2.6 \pm 0.1$ \\
2 & $50.0 \pm 1.3$ & $2.7 \pm 0.1$ & & \\
3 & $48.2 \pm 03$ & $2.6 \pm 0.1$ & & $48.1 \pm 1.1$ & $1.8 \pm 0.2$ \\
4 & $48.6 \pm 1.2$ & $2.8 \pm 0.1$ & & $43.3 \pm 1.5$ & $1.8 \pm 0.1$ \\
\hline
\end{tabular}

The leaching conditions were $t=3 \mathrm{~h} ; L / S=2.5(\mathrm{~mL} / \mathrm{g})$ each step; $\mathrm{NH}_{4}{ }^{+}: \mathrm{NH}_{3}=1: 2 ;\left[\mathrm{NH}_{4}{ }^{+}+\mathrm{NH}_{3}\right]=4 \mathrm{M}$ 
$60{ }^{\circ} \mathrm{C}$ corresponded to a zinc leaching efficiency of approximately $72 \%$. A single contact leaching experiment under the same conditions but $L / S=5$ showed a zinc leaching efficiency of $66 \mathrm{wt} \%$. From the obtained results, it appears that multiple contact leaching does not significantly boost the zinc leaching efficiency, rendering a two-step process irrelevant.

\section{Upscaling of the Leaching Process}

The optimized leaching process was up-scaled from $10 \mathrm{~mL}$ to $1 \mathrm{~L}$. The selected leaching conditions were $t=6 \mathrm{~h}$; $T=60{ }^{\circ} \mathrm{C} ; L / S=10 ; \mathrm{NH}_{4}^{+}: \mathrm{NH}_{3}=1: 2 ;\left[\mathrm{NH}_{4}{ }^{+}+\mathrm{NH}_{3}\right]=4 \mathrm{M}$. The upscaling experiment was performed using a second batch of BOF2 with composition $55.70 \pm 1.81 \mathrm{wt} \%$ iron and $5.53 \pm 0.47 \mathrm{wt} \%$ zinc. The results of the upscaling experiment showed comparable leaching yields for zinc (76 wt\% instead of $81 \mathrm{wt} \%)$ and iron $(0.7 \mathrm{wt} \%$ instead of $1.3 \mathrm{wt} \%)$. The leaching residue obtained after filtration (see Fig. S8) was dried and characterized. The zinc content of the BOF sludge was reduced from 5.5 to $1.5 \mathrm{wt} \%$, and the iron content decreased from 55.7 to $42.3 \mathrm{wt} \%$. The iron composition in the leaching residue was lower than what would be expected based on the leaching efficiency. The reason is that $\mathrm{FeO}$ from the initial residues was transformed into $\mathrm{Fe}(\mathrm{OH})_{3}$; therefore, the relative mass of the residue increased.

From the optimization and upscaling of the leaching process, it can be concluded that if the temperature/time and the total ammonia concentration are sufficiently high, a maximum zinc leaching efficiency of about $80 \%$ can be achieved. This leaching efficiency indicates the fraction of zinc present as $\mathrm{ZnO}$ or $(\mathrm{Fe}, \mathrm{Zn}) \mathrm{O}$ solid solution. The remaining zinc is present as a solid solution of magnetite and franklinite, and cannot be leached via AAC leaching. Therefore, the feasibility of the process to produce a solid residue that can be fed into the BF relies on the initial franklinite content of the BOF sludge.

\section{Purification of the PLS}

It has previously been shown in Fig. 3 that the iron in the solution precipitated as $\mathrm{Fe}(\mathrm{OH})_{3}$ by oxidation of the hexaammine iron(II) complex, $\left[\mathrm{Fe}\left(\mathrm{NH}_{3}\right)_{6}\right]^{2+}$. Therefore, the precipitation of iron from the filtered PLS was further studied as a function of time. The iron precipitation was investigated by leaving the filtered PLS in an open vial (spontaneous oxidation) and by bubbling air through the sample (forced oxidation). In both cases the concentration of iron in the PLS was measured as a function of time (Fig. 7). Although all the iron in solution could be precipitated without air addition, air bubbling clearly accelerated the process. In both cases, minor co-precipitation of zinc was observed. An XRD spectrum and an image of the obtained XRD precipitate are

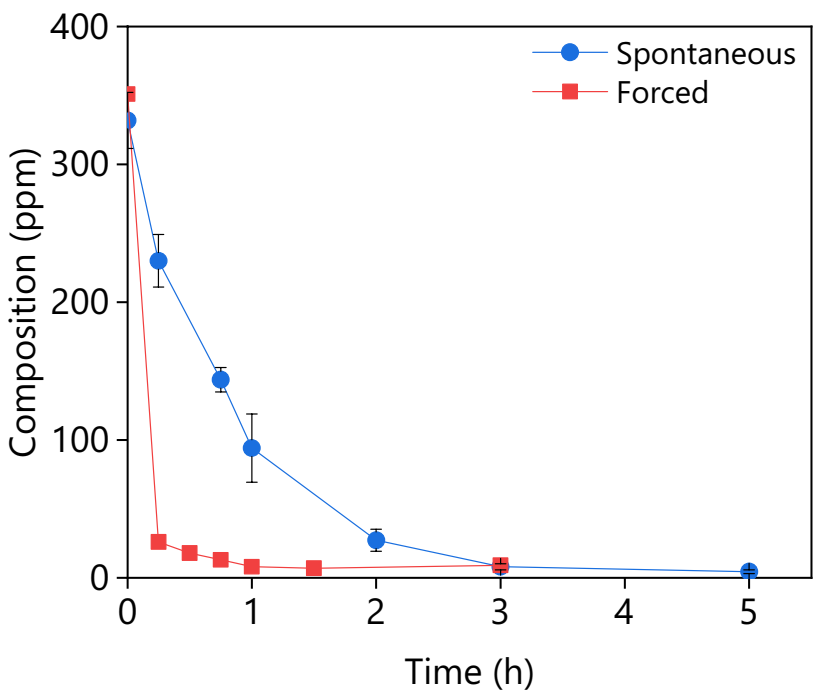

Fig. 7 Concentration of iron in the PLS as a function of time where filled circles represent spontaneous oxidation and filled squares represent forced oxidation

shown in Figs. S9 and S10, respectively. The precipitation of iron via air bubbling before filtration was also tested, and full precipitation of iron without zinc co-precipitation was achieved. The precipitation of iron after the leaching, instead of during the leaching, is preferred because it can be performed at lower temperature and avoids the evaporation of ammonia.

The recovery of the dissolved zinc from the PLS by precipitation as $\mathrm{ZnS}$ by addition of ammonium sulfide was investigated. A stoichiometric amount of ammonium sulfide could precipitate $95 \%$ of the zinc present in solution, while a $10 \%$ excess of ammonium sulfide could precipitate $100 \%$ of the zinc. The obtained precipitate was dissolved and iron could not be detected by the TXRF. Other zinc recovery methods have been reported in the literature and could be potentially applied to this process [17]. After precipitation of iron and zinc, the lixiviant can be re-used for leaching, but ammonia or ammonium carbonate make-up will be necessary to maintain the appropriate $\mathrm{NH}_{4}^{+}: \mathrm{NH}_{3}$ ratio.

\section{Conceptual Flowsheet}

Figure 8 shows a conceptual flowsheet of the process proposed in this paper. The dried BOF sludge was leached with an AAC mixture. The optimal leaching conditions were identified as $t=6 \mathrm{~h} ; T=60{ }^{\circ} \mathrm{C} ; L / S=10$; $\mathrm{NH}_{4}{ }^{+}: \mathrm{NH}_{3}=1: 2 ;\left[\mathrm{NH}_{4}{ }^{+}+\mathrm{NH}_{3}\right]=4 \mathrm{M}$. This process could leach all the zinc, except that in the form of franklinite, while only a very small fraction of iron was co-dissolved. The co-dissolved iron could be precipitated by bubbling 


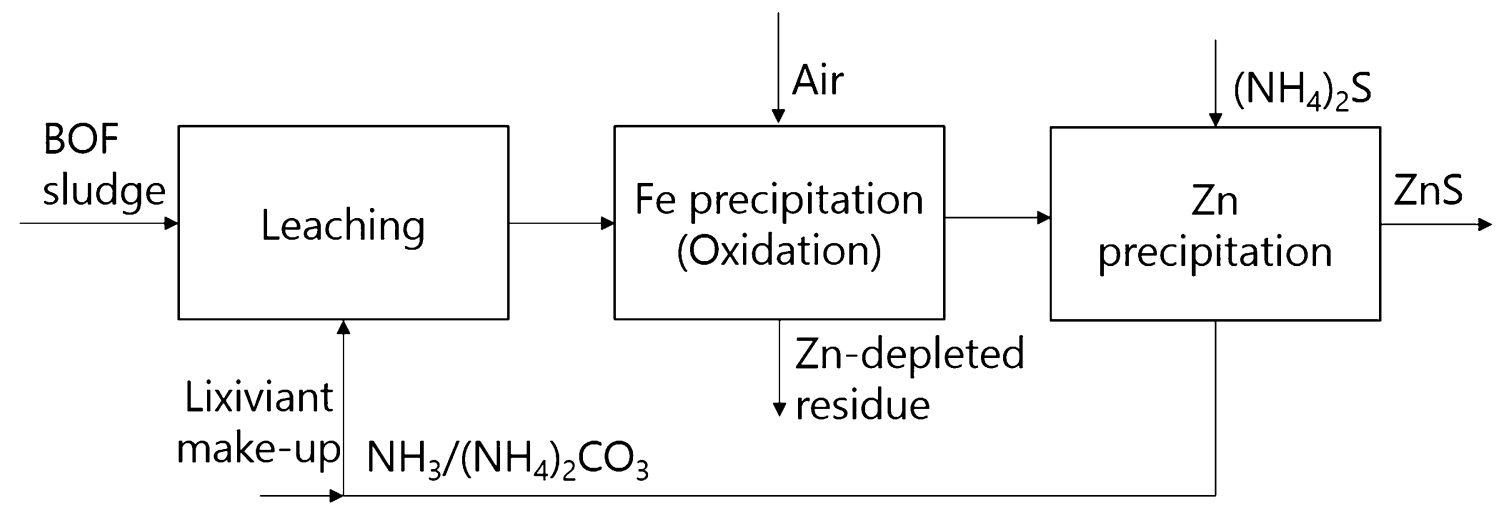

Fig. 8 Conceptual flowsheet of the AAC leaching proposed in this work

air through the PLS. The air can be bubbled directly in the leaching reactor immediately after leaching. The undissolved solids, together with the precipitated iron can be filtered and recycled to the blast furnace. The iron-free PLS was contacted with an aqueous solution of ammonium sulfide for the recovery of the dissolved zinc as zinc sulfide. The obtained zinc sulfide can be sold as a byproduct to the zinc smelting industry. The depleted lixiviant can be re-used in multiple leaching steps. A certain amount of ammonia or ammonium carbonate must be added to maintain the optimum AAC ratio.

\section{Conclusions}

The recovery of zinc from BOF sludge via ammoniacal leaching was investigated. Aqueous ammonium salt-ammonia mixtures were found to leach more zinc than either the aqueous ammonia or an aqueous ammonium salt solution. The ammonia-ammonium carbonate (AAC) mixture showed the best compromise between zinc leaching efficiency and zinc over iron leaching selectivity. The iron of the pregnant leach solution present as hexaammine iron(II) complexes was precipitated as $\mathrm{Fe}(\mathrm{OH})_{3}$ by oxidation with air. The oxidation process could be accelerated by bubbling air through the pregnant leach solution, while the dissolved zinc could be recovered as zinc sulfide by the addition of ammonium sulfide. Finally, the (almost) closed-loop process was successfully up-scaled in a $1 \mathrm{~L}$ reactor.

Unfortunately, for this specific BOF sludge the final zinc concentration in the treated BOF sludge was still too high to allow its recyclability to the blast furnace, given the extremely strict zinc constraints enforced by ArcelorMittal Bremen. Nonetheless, the presented AAC process could be suitable for other BOF sludges with lower franklinite content and/or steel plants with less strict Zn-limits for internal recycling into the blast furnace.
Acknowledgements The authors acknowledge funding from the European Institute of Innovation and Technology (EIT), a body of the European Union, under Horizon2020, under the 'KAVA Call 6', in the framework of the 'Innovation Theme' No.3 of EIT Raw Materials Project Number 19205 (SAMEX). Nerea Rodriguez Rodriguez acknowledges the financial support from the Research Foundation-Flanders (FWO, Grant nr. 12X5119N, postdoctoral fellowship).

\section{Compliance with Ethical Standards}

Conflict of interest On behalf of all authors, the corresponding author states that there is no conflict of interest.

Open Access This article is licensed under a Creative Commons Attribution 4.0 International License, which permits use, sharing, adaptation, distribution and reproduction in any medium or format, as long as you give appropriate credit to the original author(s) and the source, provide a link to the Creative Commons licence, and indicate if changes were made. The images or other third party material in this article are included in the article's Creative Commons licence, unless indicated otherwise in a credit line to the material. If material is not included in the article's Creative Commons licence and your intended use is not permitted by statutory regulation or exceeds the permitted use, you will need to obtain permission directly from the copyright holder. To view a copy of this licence, visit http://creativecommons.org/licenses/by/4.0/.

\section{References}

1. Worldsteel (2010) Steel industry by-products: project group report 2007-2009. Brussels

2. Naiyang M, William S (2020) Enhancement of in-plant recycling of integrated steel mill offgas solid wastes by reallocating crucial zinc-bearing materials. J Clean Prod 251:119783. https ://doi.org/10.1016/j.jclepro.2019.119783

3. Cantarino MV, de Carvalho FC, Borges Mansur M (2012) Selective removal of zinc from basic oxygen furnace sludges. Hydrometallurgy 111-112:124-128. https://doi.org/10.1016/j.hydro met.2011.11.004

4. Sammut ML, Rose J, Masion A et al (2008) Determination of zinc speciation in basic oxygen furnace flying dust by chemical extractions and X-ray spectroscopy. Chemosphere 70:19451951. https://doi.org/10.1016/j.chemosphere.2007.09.063

5. Wang L, Huang Y, Lu X (2013) Zn distribution and speciation in zinc-containing steelmaking wastes by synchrotron radiation 
induced $\mu$-XRF and $\mu$-XANES spectroscopy. J Phys Conf Ser 430:12097. https://doi.org/10.1088/1742-6596/430/1/012097

6. Wang L, Lu X, Huang Y (2013) Determination of Zn distribution and speciation in basic oxygen furnace sludge by synchrotron radiation induced $\mu$-XRF and $\mu$-XANES microspectroscopy. X-Ray Spectrom 42:423-428. https://doi.org/10.1002/ xrs. 2494

7. Singh AKP, Raju MT (2011) Recycling of basic oxygen furnace (BOF) sludge in iron and steel works. Int J Environ Technol Manag 14:19-32. https://doi.org/10.1504/IJETM.2011.039255

8. Trung ZH, Kukurugya F, Takacova $Z$ et al (2011) Acidic leaching both of zinc and iron from basic oxygen furnace sludge. J Hazard Mater 192:1100-1107. https://doi.org/10.1016/j.jhazm at.2011.06.016

9. Kelebek S, Yörük S, Davis B (2004) Characterization of basic oxygen furnace dust and zinc removal by acid leaching. Miner Eng 17:285-291. https://doi.org/10.1016/j.mineng.2003.10.030

10. Hoang Trung Z, Kukurugya F, Takáčová Z et al (2010) Leaching of basic oxygen furnace sludge with sulphuric acid. Acta Montan Slovaca Ročník 15:200-203. https://doi.org/10.1016/j.jhazm at.2011.06.016

11. Vereš J, Jakabský Š, Lovás M, Hredzák S (2010) Non-isothermal microwave leaching kinetics of zinc removal from basic oxygen furnace dust. Acta Montan Slovaca Ročník 15:204-211

12. Duval LA, Road H (1965) Process for removing zinc oxide from iron oxide flue dust by the use of spent pickle liquor. US Patent 3,375,069

13. Wang J, Wang Z, Zhang Z, Zhang G (2019a) Zinc removal from basic oxygen steelmaking filter cake by leaching with organic acids. Metall Mater Trans B 50:480-490. https://doi.org/10.1007/ s11663-018-1440-3

14. Wang J, Wang Z, Zhang Z, Zhang G (2019b) Removal of zinc from basic oxygen steelmaking filter cake by selective leaching with butyric acid. J Clean Prod 209:1-9. https://doi.org/10.1016/j. jclepro.2018.10.253

15. Gargul KJ, Małecki P (2016) Alkaline leaching of low zinc content iron-bearing sludges. Arch Metall Mater 61:43-50. https:// doi.org/10.1515/amm-2016-0013

16. Nyirenda RL, Lugtmeijer AD (1993) Ammonium carbonate leaching of carbon steelmaking dust. detoxification potential and economic feasibility of a conceptual process. Miner Eng 6:785-797. https://doi.org/10.1016/0892-6875(93)90009-C

17. Harvey TG (2006) The hydrometallurgical extraction of zinc by ammonium carbonate: a review of the Schnabel process. Miner Process Extr Metall Rev 27:231-279. https://doi. org $/ 10.1080 / 08827500600815271$

18. Gargul K, Boryczko B (2015) Removal of zinc from dusts and sludges from basic oxygen furnaces in the process of ammoniacal leaching. Arch Civ Mech Eng 15:179-187. https://doi. org/10.1016/j.acme.2014.08.004

19. Song K, Yuan J, Shen P et al (2018) Research on leaching performance of low grade zinc oxide ore in the system of
$\left(\mathrm{NH}_{4}\right)_{2} \mathrm{SO}_{4}-\mathrm{NH}_{3}-\mathrm{H}_{2} \mathrm{O}$. IOP Conf Ser Earth Environ Sci 170:22114. https://doi.org/10.1088/1755-1315/170/2/022114

20. Ruiz O, Clemente C, Alonso M, Alguacil FJ (2007) Recycling of an electric arc furnace flue dust to obtain high grade $\mathrm{ZnO}$. J Hazard Mater 141:33-36. https://doi.org/10.1016/j.jhazm at.2006.06.079

21. Varga T, Török T (2013) Experimental investigation of zinc precipitation from EAF dust leaching solutions. Mater Sci Eng 38:61-71

22. Peters MA (1976) Process for recovering zinc from steelmaking flue dust, US 4,071,357

23. Olper M, Maccagni M (2008) From C.Z.O. to Zinc Cathode Without any Pretreatment. The Ezinex Process. In: Lead and Zinc 2008. The Southern African Institute of Mining and Metallurgy

24. Filippou D (2004) Innovative hydrometallurgical processes for the primary processing of zinc. Miner Process Extr Metall Rev 25:205-252. https://doi.org/10.1080/08827500490441341

25. Ma A, Zhang L, Peng J et al (2016) Extraction of zinc from blast furnace dust in ammonia leaching system. Green Process Synth 5:23-30. https://doi.org/10.1515/gps-2015-0051

26. Jha MK, Kumar V, Singh RJ (2001) Review of hydrometallurgical recovery of zinc from industrial wastes. Resour Conserv Recycl 33:1-22. https://doi.org/10.1016/S0921-3449(00)00095-1

27. Peeters T, Zhang F, Yang Y (2016) Process for selective removal of zinc from metallurgical plant, European Patent EP 3333272 A1

28. Riaño S, Regadío M, Binnemans K, Vander Hoogerstraete T (2016) Practical guidelines for best practice on total reflection $\mathrm{X}$-ray fluorescence spectroscopy: analysis of aqueous solutions. Spectrochim Acta Part B 124:109-115. https://doi.org/10.1016/j. sab.2016.09.001

29. Ding Z, Chen Q, Yin Z, Liu K (2013) Predominance diagrams for $\mathrm{Zn}(\mathrm{II})-\mathrm{NH}_{3}-\mathrm{Cl}-\mathrm{H}_{2} \mathrm{O}$ system. Trans Nonferrous Met Soc China 23:832-840. https://doi.org/10.1016/S1003-6326(13)62536-4

30. Klocke DJ, Hixson AN (1972) Solubility of ferrous iron in aqueous ammoniacal solutions. Ind Eng Chem Process Des Dev 11:141-146. https://doi.org/10.1021/i260041a028

31. Mena M, Olson FA (1985) Leaching of chrysocolla with ammonia-ammonium carbonate solutions. Metall Trans B 16:441-448. https://doi.org/10.1007/BF02654842

32. Yang S, Tang $\mathrm{M}$ (2000) Thermodynamics of $\mathrm{Zn}(\mathrm{II})-\mathrm{NH}_{3}-\mathrm{NH}_{4} \mathrm{Cl}-$ $\mathrm{H}_{2} \mathrm{O}$ system. Trans Nonferrous Met Soc China 10:830-833

33. Dutra AJB, Paiva PRP, Tavares LM (2006) Alkaline leaching of zinc from electric arc furnace steel dust. Miner Eng 19:478-485. https://doi.org/10.1016/j.mineng.2005.08.013

Publisher's Note Springer Nature remains neutral with regard to jurisdictional claims in published maps and institutional affiliations.

\section{Affiliations}

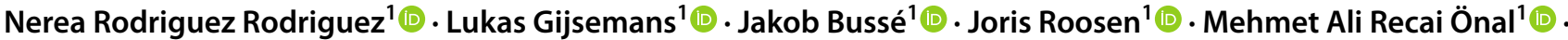

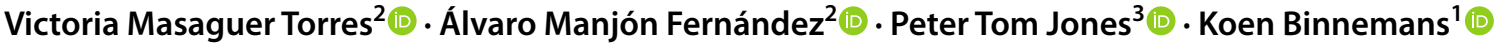

Koen Binnemans

koen.binnemans@kuleuven.be

1 Department of Chemistry, KU Leuven, Celestijnenlaan 200F, P.O. Box 2404, 3001 Leuven, Belgium
2 ArcelorMittal Global R\&D Asturias, Marques de Suances s/n - Apartado 90, 33400 Avilés, Spain

3 Department of Materials Engineering, KU Leuven, Kasteelpark Arenberg 44, Box 2450, 3001 Leuven, Belgium 